AJChE 2020, Vol. 20, No. 2, 154 - 164

\title{
Mathematical Model for Agglomeration Process of Milk Powder
}

\section{S. Auamwong ${ }^{1}$}

\section{T. Rohitatisha Srinophakun *,2}

${ }^{1}$ Chemical Engineering Practice School, Department of Chemical Engineering, King Mongkut's University of Technology Thonburi, Bangkok, Thailand

${ }^{2}$ Department of Chemical Engineering, Kasetsart University, Bangkok, Thailand e-mail: fengtcs@ku.ac.th

Stickiness during milk spray drying can lead to the agglomeration of milk powder and damage the processing equipment. A mathematical model can achieve a better understanding. In this work, the Distinct Element Method (DEM) simultaneously with Computational Fluid Dynamics (CFD) was used to describe skim milk powder's agglomeration process. The study comprised 2 parts: surface stickiness mechanism and agglomeration of sticky powder. Start with particle formation, the droplet size, and the number of particles produced can be calculated and used to predict the droplet's surface stickiness. These reveal the effect of moisture content, droplet surface temperature, droplet size after drying, and sticky point temperature. Then, the agglomeration of sticky powder inside the spray chamber was predicted. Besides, the particle and fluid motion inside the spray chamber were also determined. Then, the particle size distribution after agglomeration was obtained. Furthermore, parts of the model were validated with the experimental data of Williams et al. (2009), which has three different droplet sizes, 56.8, 78.28 , and 108.5 micrometers. The results gave the same trend as the sticky surface of the powder. The droplet's moisture contents rapidly decreased in the first period and fell to a critical value, which was $0.044,0.048$, and $0.061 \mathrm{~kg}$ water $/ \mathrm{kg}$ solid, respectively. The periods of a sticky surface were around $0.033,0.03$, and 0.024 seconds. The largest droplet size was selected for the study of the agglomeration process. This model could predict the agglomeration of sticky powder since there were 216 from 900 droplets agglomerated. Moreover, the largest droplet size was 100.6 micrometers, and the most popular was 79.9 micrometers, which were the size of the un-agglomerated powder.

Keywords: Agglomeration, Computational Fluid Dynamics (CFD), Distinct Element Method (DEM), Skim milk powder/ Stickiness

\section{INTRODUCTION}

In powder processing, powder agglomeration may occur during the spray drying operation (Riedel et al. 2020). The agglomeration of powder may be a desired and undesired process. The desired process, can be a beneficial process for controlling the enlargement of particles to improve powder properties and obtain 
high-quality products. However, it may be undesirable because of uncontrolled development, solidifying, spanning, or lumping, which can be issued customarily experienced during the shower drying activity. The agglomerated particle's attachment can be developed either the crystallization or by the particle's surface stickiness (Phosanam et al. 2020).

The quick evacuation of water in splash drying activity brings about indistinct development, which can be influenced by the powder quality. High temperatures or leftover water substance in the drying cycle may cause tenacity, solidifying, and agglomeration of powder particles and grip of the powder particles to the handling hardware, which can restrict splash drier run lengths (Pombo et al., 2020). Therefore, it is imperative to have the option to distinguish the necessary conditions that cause tenacity to happen when particles interact with one another or with the gear surface.

To date, several works on agglomeration and stickiness of milk powder have been investigated. However, field observation in the literature only studies agglomeration and stickiness of milk powder through the experiment. Many techniques have been developed for measuring the initiation of stickiness in milk powder. Oskan et al. (2002) described tenacity and cake arrangement in entire and skim milk powders by utilizing a viscometer strategy, which depends on the estimation of the force needed to transform a propeller embedded into milk powders and an entrance test dependent on the estimation of the power needed to infiltrate milk powder compacts. Relevant research, such as Static and Dynamic Stickiness Tests to Measure Particle Stickiness (Sewalt et al. 2020). In 2005, the blow tester technique was developed by Paterson et al. (2005) to measure stickiness development with time. Paterson and Bronlund (2007) developed a new device for measuring stickiness initiation in dairy powder, the particle gun technique. This technique mimics the particle experience during spray drying and transport, making the outcomes straightforwardly pertinent to the business. A few factors can undoubtedly impact tenacity conduct, such as temperature and relative moistness of gulf air, the underlying powder water action, and the undefined lactosecontaining glass progress temperature in milk powder. Relevant articles such as Drying Kinetics and Particle Formation from Dilute Colloidal Suspensions in Aerosol Droplets were available elsewhere (Archer et al. 2020).

The powder agglomerate process in the spray chamber due to a liquid bridge formation between particles can be described by a combined approach of distinct element method and computational fluid dynamics (DEM-CFD). According to this combined method, the movement of individual particles is obtained by understanding Newton's second law of movement and gas stream by the Navier-Stokes condition dependent on the idea of the neighborhood ordinary. This combined technique's benefit is that the molecule and smooth movement data can be gotten in more detail than that from the trial without upsetting the framework by estimating hardware. However, this method still has a disadvantage of long 
computational time.

The modeling of the agglomeration and stickiness phenomena in milk powder is still at an early investigated stage. As a result, this work is particularly interesting to formulate a mathematical model for predicting the agglomeration process in milk powder. In this work, the proposed mathematical is divided into 4 parts; particle formation, prediction of droplet's surface stickiness, agglomeration of sticky powder, and particle size distribution.

\section{MATERIALS AND METHODS}

\section{Modeling of particle formation}

In this model, the pressure nozzle atomization is considered. Therefore, the sprayed droplet size and the number of particle formation will be determined from Eq. (1) to Eq. (5) (Filkova et al., 2007) based on the following assumptions

- The droplet produced from pressure nozzle atomization has a spherical shape.

- All of the droplets produced have the same size.

$D_{p}=286\left[\left(2.54 \times 10^{-2}\right) D+\right.$

$0.17] \exp \left[\frac{39}{v_{a x}}-\left(3.13 \times 10^{-3}\right) v_{1}\right]$

$v_{a x}=\frac{D_{1}^{2}}{2 D b} v_{1}$

$v_{1}=\frac{\dot{V}_{1}}{A_{1}}$

$b=2.7\left[\frac{D F_{N} \mu_{L}}{\left(\Delta P_{L} \rho_{L}\right)^{0.5}}\right]$

$F_{N}=\frac{m_{L}}{\left(\Delta P_{L} \rho_{L}\right)^{0.5}}$

\section{Modeling of surface stickiness of droplet}

1. Drying kinetics for a single droplet
The drying behavior of a single droplet in the first drying stage of Adhikari et al. (2005) is considered to formulate the mathematical model of stickiness in skim milk powder.. This model is based on the whole droplet's drying kinetics to estimate the surface moisture content and temperature. It empowers the glass change temperature $\left(T_{g}\right)$ of the surface layer to be assessed. The model was created dependent on the accompanying suppositions:

- The bead is a non-empty circle.

- It shrivels consistently with loss of water (ideal shrinkage).

- There are no temperature inclinations inside the bead.

- Moisture move inside the bead is by sub-atomic dissemination.

- Heat move to the bead is exclusively by convection.

- There is no isolation of solids inside the bead.

- The bead is pseudo-twofold in the organization (i.e., water and solids).

1.1 Prediction of moisture and droplet surface temperature

The distribution of the moisture $\left(X_{w}\right)$ within the droplet is determined by the convective diffusion equation, where $X_{w}$ depends on both radius position inside the droplet and time. The droplet surface temperature ( $\mathrm{Td}$ ) is developed from the energy balance around the droplet.

$$
\begin{aligned}
\frac{\partial X_{w}}{\partial t} & =\frac{1}{r^{2}} \frac{\partial}{\partial r}\left(D_{w}\left(X_{w}, T\right) r^{2} \frac{\partial X_{w}}{\partial r}\right) \\
\frac{d T_{d}}{d t} & =\frac{4 \pi R^{2}\left[h_{g}^{*}\left(T_{a}-T_{d}\right)-\Delta H_{v} F\right]}{m_{s}\left(X_{w} c_{p, w}+c_{p, s}\right)}
\end{aligned}
$$


$F=K_{g}^{*} \frac{M_{w}}{R_{G}} \frac{P_{T}}{T_{a v}} \ln \left(\frac{1-\frac{P_{v, d b}}{P_{T}}}{1-\frac{a_{w} P_{v s, T d}}{P_{T}}}\right)$

The initial and boundary conditions required for solving all of the equations are shown below.

Initial condition:

at $\mathrm{t}=0$ and $0<\mathrm{r}<\mathrm{R} ; X_{w}=X_{w o}$ and $T_{d}=T_{d, o}$

Boundary condition 1:

at $\mathrm{t}>0$ and $\mathrm{r}=0 ; \quad \frac{\partial X_{w}}{\partial r}=0$

Boundary condition 2:

at $\mathrm{t}>0$ and $\mathrm{r}=\mathrm{R} ;\left(D_{w}\left(X_{w}, T\right) C_{s} \frac{\partial X_{w}}{\partial r}\right)=-F$

\subsection{Glass transition temperature}

Glass progress temperature $\left(T_{g}\right)$ is the most significant descriptor of the properties of indistinct polymers. It is the temperature at which the shapeless stage is changed over among rubbery and smooth states. The conveyance of $\mathrm{T}_{\mathrm{g}}$ inside the bead can be resolved to utilize the GordonTaylor condition (Gordon et al., 1952), which is re-written as far as dampness $\left(X_{w}\right)$ and is given by Eq. (9).

$T_{g}=\frac{\left[\left(1-X_{w}\right) T_{g, l a c t}+X_{w} T_{g, w a t e r}\right]}{\left(1+7.48 X_{w}\right)}$

\subsection{Sticky point temperature}

Clingy point temperature is utilized to foresee if the outside of the material is clingy or not. It depends on the way that for a given blend of material temperature and dampness content, the mass of a delicate material opposes development and is not, at this point, free-streaming. At the clingy point temperature, the powder particles show the highest inclination to adhere to hardware surfaces or one another. This work is characterized as an actual temperature, which is $31^{\circ} \mathrm{C}$ over the glass change temperature, which depends on the test information of the tenacity conduct of skim milk powder tried by molecule weapon procedure.

$T_{\text {sticky }}=T_{g}+31$

\section{Modeling of agglomeration of sticky powder}

Since the agglomeration of powder occurs when there is a collision of sticky powder, the particle motion and fluid motion inside the spray chamber will be considered. A combined approach of distinct element method and computational fluid dynamics (DEM-CFD) will describe the particle motion and fluid motion. The necessary assumptions are made to simplify the model.

- The spray drying chamber is assumed to have a cubic shape.

- Droplet sprayed from pressure nozzle atomization has a hollow cone spray pattern.

- The airflow pattern inside the spray drying chamber is co-current.

- Heat and mass transfer of the droplet comes from the drying kinetics for a single droplet.

- No hygroscopic slim permeable media fit as a fiddle is accepted for the particles.

- Particles should have a delicate circle association communicated by a Hookean natural spring, a dashpot, and a grating slider with Coulomb's grinding law.

- Gas is inviscid aside from while thinking about the liquid delay a molecule. 
- Physical properties, for example, the warm conductivity, thickness, and consistency of the gas and warmth limit of the molecule, are consistent.

- Particle-to-molecule heat move is disregarded on account of short contact time. All of the un-agglomerated powders have the same surface properties.

- The agglomerated powders still have the same spherical shape.

- The mass of the agglomerated powder comes from the total mass of the collision powders.

- The temperature of agglomerated powder is weighted by mass.

- Heat misfortune through the bed divider is disregarded.

The calculations that will be utilized to anticipate the agglomeration of powder in this model have appeared in Fig. 1.

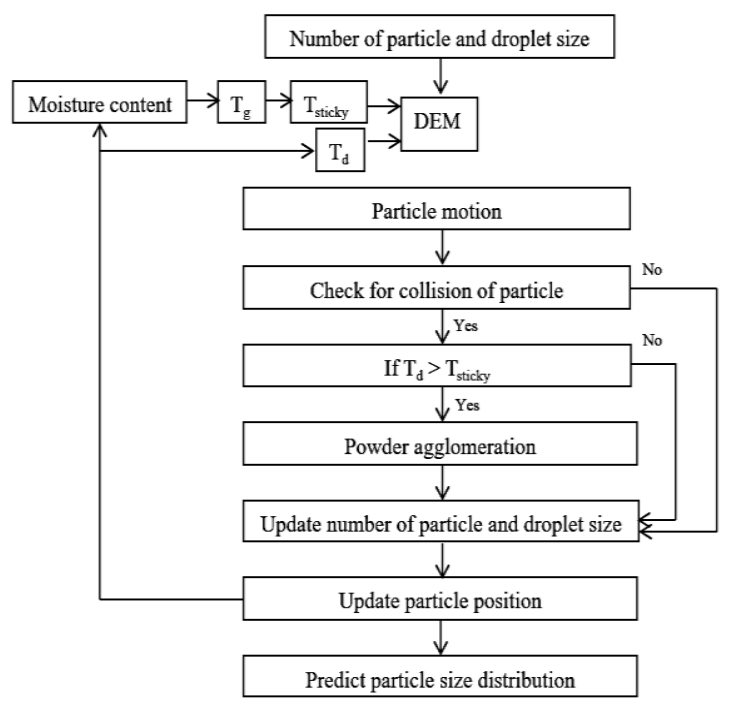

Fig. 1: Algorithm of the prediction of powder agglomeration

\section{RESULTS AND DISCUSSION}

1. Surface stickiness results
The moisture content result was validated with the experimental result of Ferrari et al. (1989), which studied the drying kinetics of skim milk powder.

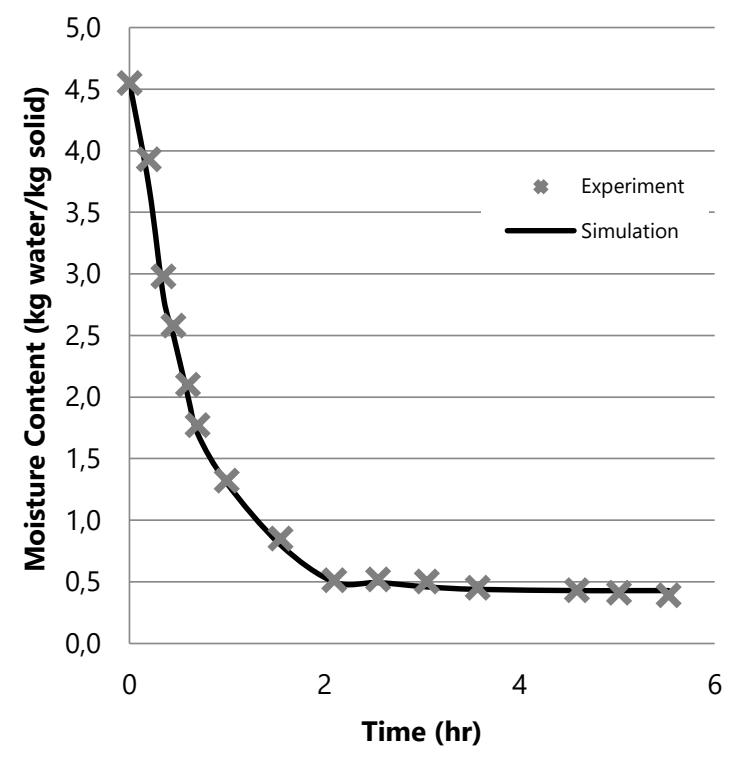

Fig. 2: The comparison of moisture content of skim milk powder between simulation and experiment of Ferrari et al. (1989).

From Fig. 2, the result from the model gave an error of around $3 \%$, which is acceptable. For droplet surface temperature results, the model was validated with the experimental result of Chen et al. (2004), which study the drying behavior of whole milk powder. The model's result gave the error of around $10 \%$, as seen in Fig. 3 compared with the experimental result since the equation from this model was developed to predict the drying kinetics of skim milk powder. The equations used in the model showed the relation between the droplet surface temperature and moisture content. Although the model did not show a satisfactory prediction of whole milk powder's droplet surface temperature, the model showed an acceptable prediction of 
skim milk powder's moisture content. Therefore, this model is proper to predict the drying kinetics of skim milk powder.

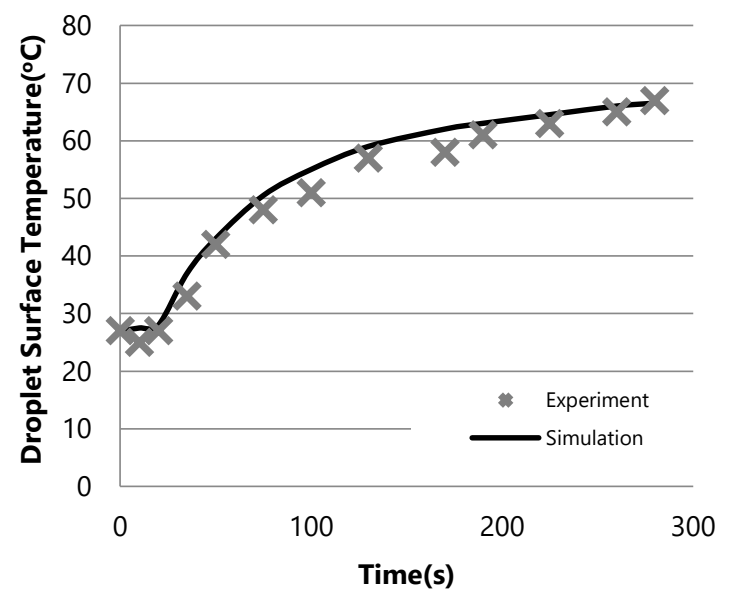

Fig. 3: The comparison of droplet surface temperature of whole milk powder between simulation and experiment of Chen et al. (2004).

After the model was approved, this model will be utilized to foresee skim milk powder's drying energy. The conveyance of dampness inside a drying bead, the bead surface temperature, the clingy point temperature, and the bead size in the wake of drying can be resolved.

When the showered bead contacts with hot air, the vanishing of water at the bead surface happens, bringing about the quickly diminishing bead dampness content in the main time frame. From that point onward, the bead's dampness substance tumbles to the necessary incentive at the time 0.028 seconds, individually. The firm outside layer will shape at the bead surface, and there is no dissipation of water at the drop surface. As appeared in Fig. 4, the slant toward the finish of every-three cases does not change with time.

Fig. 5 shows the connection between the bead surface temperature and time. The underlying bead surface temperature is $55^{\circ} \mathrm{C}$. In the primary time frame, the bead surface temperature somewhat increments from the underlying incentive with time since a large portion of the warmth move to the bead is utilized to dissipate water at the drop surface.

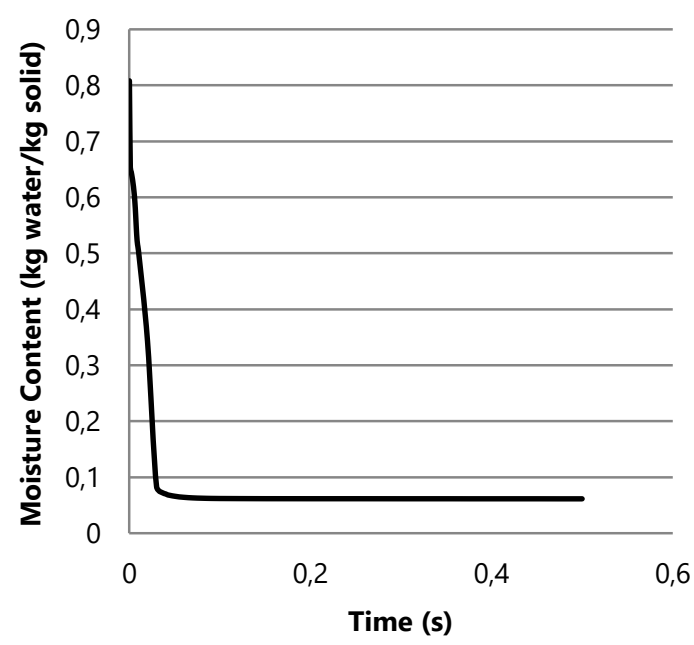

Fig. 4: Moisture content of skim milk powder size $108.5 \mu \mathrm{m}$

When the bead's dampness substance tumbles to the fundamental worth, and the dissipation of water at the drop surface does not happen, the warmth move from hot air to drop will be utilized in warming the drop. The reason for bead surface temperature expansion originates from its good warmth, as it were.

During the first period, the simulation showed that the higher the moisture content in a droplet, the lower the sticky point temperature. When the evaporation occurs, the droplet's sticky point temperature will increase with the decrease in moisture content.

Then, the sticky point temperature does not change after evaporation is done. 
The bead size relies upon the measure of water containing in a drop. When the bead is warmed with hot air, water dissipation starts from the drop surfaces, bringing about the dampness content decline. The cycle of water dissipation brings about shrinkage of the bead distance across (Mezhericher et al., 2008). In the simulation, the moisture content decreases suddenly, which will result in a rapidly decreasing droplet size. When the moisture content does not decrease with time, the droplet size will have a constant diameter at $80 \mu \mathrm{m}$.

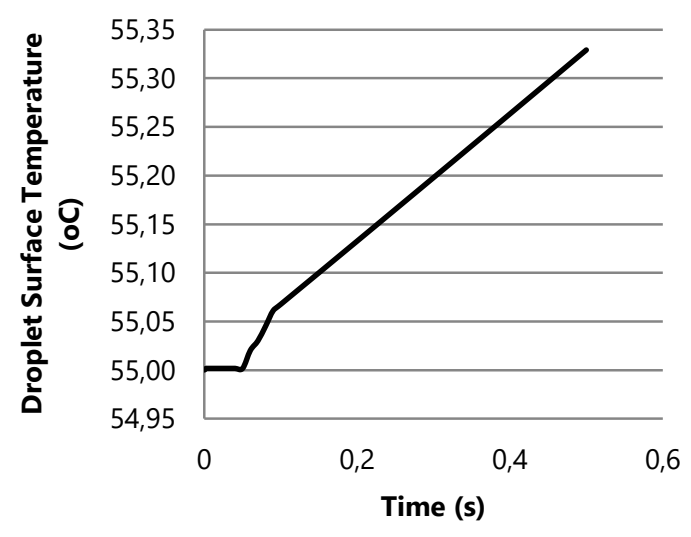

(a)

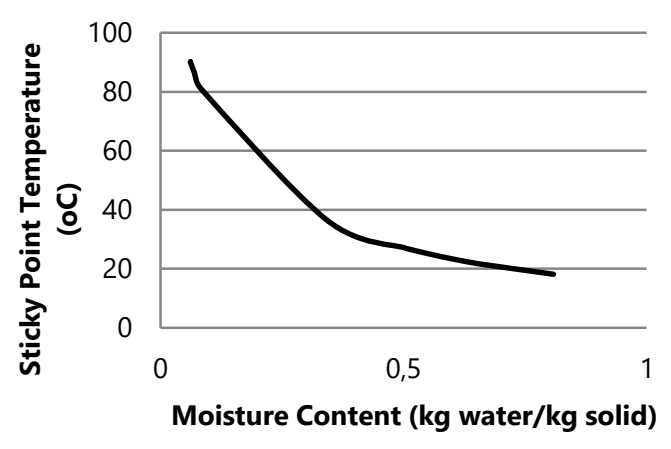

(b)

Fig. 5: (a) Droplet surface temperature of skim milk powder size $108.5 \mu \mathrm{m}$ (b) Sticky point temperature of skim milk powder size $108.5 \mu \mathrm{m}$ with moisture content

Fig. 6 shows the relationship between droplet size and time. The bead surface temperature and the clingy point temperature will be considered to anticipate the bead's surface tenacity. Theoretically, the droplet will have a sticky surface when the droplet surface temperature higher than the sticky point temperature (Murti et al., 2009).

Therefore, this work will follow this theory as a criterion to identify the sticky surface of the droplet-basically, the clingy point temperature increments when the dampness content abatement. Hence, the sticky point temperature was lower than the droplet surface, causing the droplet to have stickiness surface at the beginning of the simulation.

When the dissipation of water at the bead surface happened, the clingy point temperature quickly expanded and was higher than the drop surface temperature. Therefore, the droplet will not have a sticky surface.

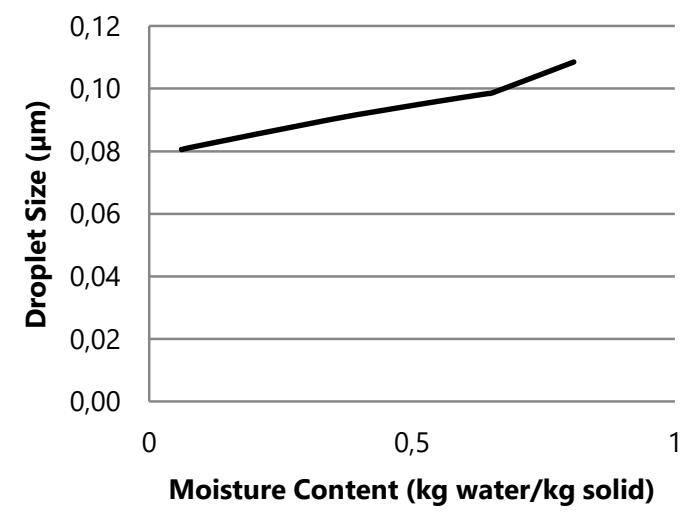

Fig. 6: The droplet size of skim milk powder size $108.5 \mu \mathrm{m}$ with moisture content

The period that the droplet will have a sticky surface is short; this can be observed from Fig. 7 since the evaporation of water at the droplet surface and the rapid decrease in moisture content's critical 
value. The period that the droplet will have a sticky surface is 0.024 seconds.

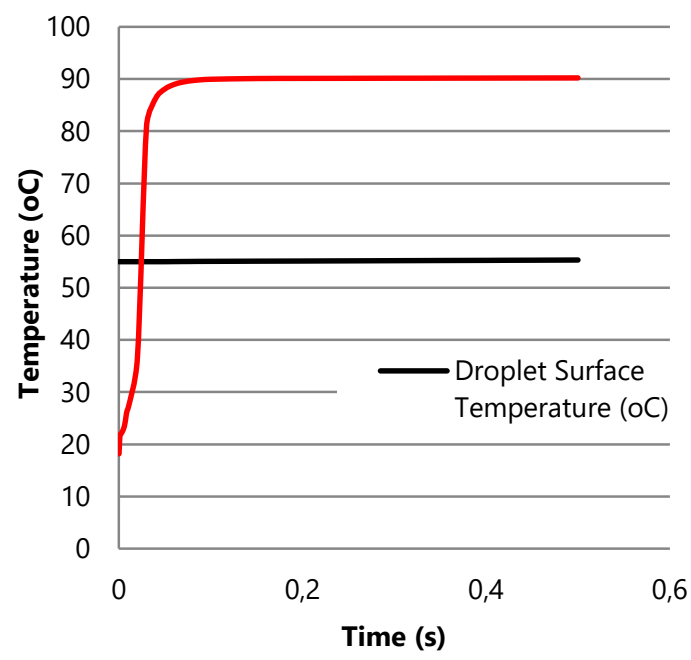

Fig. 7: Droplet surface temperature and sticky point temperature of skim milk powder size $108.5 \mu \mathrm{m}$ with time

\section{Agglomeration of sticky powder results}

For predicting the agglomeration of sticky powder, the particle movement inside the sprayed chamber is significant. This part will simulate the particle movement inside the spray drying chamber. The drying of the droplet is also considered the agglomeration of sticky particles. In this work, 900 droplets of skim milk are sprayed from the pressure nozzle with the hollow cone spray pattern. The droplets are sprayed three times for 3 seconds, with 300 droplets per second. The changing of droplet size and droplet surface temperature is considered.

From the result, it can be observed that there was the agglomeration of some sticky particles occurred in the beginning after droplets were sprayed. The model results also showed that this model could predict the sticky droplets' agglomeration since there are 216 from 900 droplets agglomerated in this work. Moreover, it can predict the movement of the particle inside the spray drying chamber.

In this work, particle size distribution is used to represent the droplet size after simulation. The results showed that most of the droplet size after drying was $79.9 \mu \mathrm{m}$, which was the droplet size at the unagglomerated droplet's critical moisture content. Moreover, some droplets had a larger size than $79.9 \mu \mathrm{m}$ because of the agglomeration of the sticky droplet. The larger size found from this model was 100.6 $\mu \mathrm{m}$, which was the agglomerated droplet's size, and the particle size distribution is shown in Fig. 8.

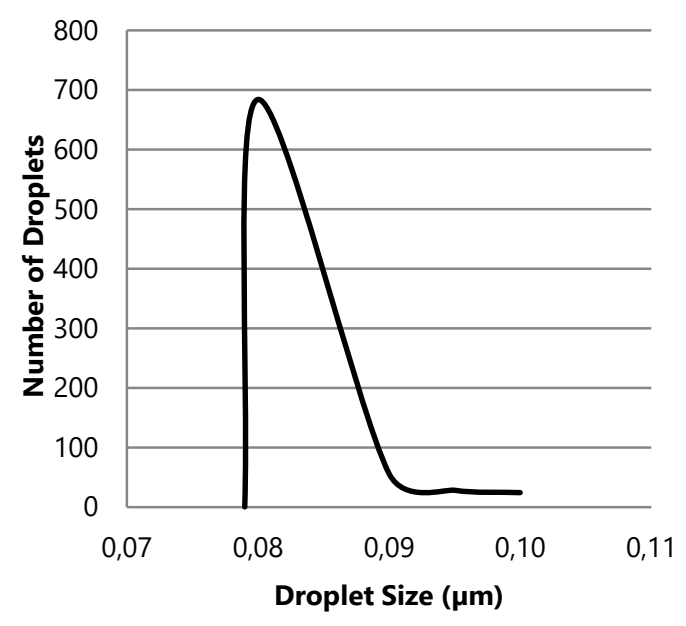

Fig. 8: Particle size distributions after agglomeration of droplet size $0.08 \mu \mathrm{m}$

\section{CONCLUSIONS}

In this work, the mathematical model was set up to explain the agglomeration and stickiness phenomena. The mathematical model was divided into four major parts. The first part is the model to calculate the number of particle formation. In this step, the droplet size produced from pressure nozzle atomization was 
determined and used to calculate the number of particle formation. The second part was the model to predict the surface stickiness of the droplet. This part utilized the warmth and mass exchange of a solitary bead during the shower drying cycle to clarify the dampness content profile, droplet surface temperature, droplet size after drying, and the sticky point temperature. These two models were programmed. Next, the model to predict sticky powder's agglomeration was developed by considering a solitary bead's drying energy and the molecule development inside the splash drying chamber. This aspect of the model depended on the blended approach of DEM-CFD and was created by the Clanguage program with standard capacity from business programming. The DEM was applied to figure the position, the connection powers between molecule and molecule divider contact. From that point onward, Newton's second law of movement was applied to ascertain the molecule movement. CFD was used to calculate the fluid motion based on average local quantities inside the spray drying chamber. In addition, the concept of sticky point temperature was used as the criteria for the sticky droplets to agglomerate. Then, the results from this part were shown in the animation style to illustrate the particle size distribution.

The model to calculate the number of particle formation was developed first and validated with the experiment of Williams et al. (2009) for the model's accuracy. Three experiment cases were selected and studied in this model, with droplet sizes equals to $56.8,78.28$, and $108.5 \mu \mathrm{m}$. The results showed that the programming gives the droplet size realistic results from pressure nozzle atomization. After predicting the droplet size, the number of particle formation was calculated. Because of insufficient experimental data, these results cannot be validated. Next, three cases of droplet size were determined for the drying kinetics. The results are the droplet moisture content, the droplet surface temperature, droplet size after drying, and sticky point temperature. From the case three results, which droplet size equal to $108.5 \mu \mathrm{m}$, the moisture content of droplet rapidly decreased from the beginning at $0.808 \mathrm{~kg}$ water $/ \mathrm{kg}$ stable in the first simulation period and then fell to $0.06 \mathrm{~kg}$ water $/ \mathrm{kg}$ solid. Since there is a loss of moisture content, the droplet size's shrinkage resulting from water evaporation occurred, which gave the droplet size equal to $80 \mu \mathrm{m}$. When considered the droplet surface temperature, it slightly increased in the beginning from $55{ }^{\circ} \mathrm{C}$. After the moisture content fall, the droplet surface temperature still increased as it heated with hot air. It was lower than the droplet surface for sticky point temperature, causing the droplet to have stickiness surface at the beginning of the simulation. After that, the sticky point temperature was higher than the droplet surface temperature due to of decreasing moisture content. Therefore, the droplet will not have a sticky surface. The results in the case of droplet size equal to $108.5 \mu \mathrm{m}$ were also used in agglomeration prediction. The model showed the possibility in the prediction of agglomeration since the droplets inside the spray chamber agglomerated. From the results, there are 216 from 900 droplets 
that agglomerated during the simulation. Moreover, the largest size of the agglomerated particle after drying was $100.6 \mu \mathrm{m}$, and the smallest size was 79.9 $\mu \mathrm{m}$, which was the size of the unagglomerated droplets.

\section{ACKNOWLEDGEMENT}

Centre of Excellence has supported this research for Petroleum, Petrochemicals, and Advanced Materials and Chemical Engineering Practice School (ChEPS), King Mongkut's University of Technology Thonburi, and Institute of Technology and Engineering, Massey University.

\section{REFERENCES}

1. Mezhericher, M., Levy, A., Boorde, I., (2008), "Heat and mass transfer of single droplet/wet particle drying", Chem. Eng. Sci., Vol. 63, pp. 12-23.

2. Riedel, F., Düsenberg, B., Schmidt, J., Bück, A., and Peukert, W. (2020). "Production of PBT/PC multi-material particles via a combination of cogrinding and spray-agglomeration for powder bed fusion". Procedia CIRP, Vol.94, pp. 100-104.

3. Phosanam, A., Chandrapala, J., Huppertz, T., Adhikari, B., and Zisu, B. (2020). "Changes in physicochemical and surface characteristics in model infant milk formula powder (IMF) during storage". Drying Technol., pp.111.

4. Pombo, J. C. P., de Medeiros, H. H. B. R., and da Silva Pena, R. (2020). "Optimization of the spray drying process for developing cupuassu powder". J. Food Sci. Technol., Vol 57, pp. 4501-4513

5. Sewalt, E. J., Zhang, F., van Steijn, V., van Ommen, J. R., and Meesters, G. M. (2020) "Static and Dynamic Stickiness Tests to Measure Particle Stickiness". KONA Powder and Particle Journal, 2021017.

6. Archer, J., Walker, J., Gregson, F. K., Hardy, D. A., \& Reid, J. P. (2020). "Drying Kinetics and Particle Formation from Dilute Colloidal Suspensions in Aerosol Droplets". Langmuir.

7. Ferrari, G., Meerdink, G., and Walstra, P., (1989), "Drying kinetics for a single droplet of skim milk", Journal of Food Engineering, Vol. 10, pp. 215-230.

8. Chen, X.D., and Lin, S.X.Q., (2004), "The reaction engineering approach to modeling drying of milk droplets", Drying'2004-Proceedings of the 14th International Drying Symposium (IDS'2004), Vol. C, pp. 1644-1651.

9. Williams, A.M., Jones, J.R., Paterson, A.H.J., and Pearce, D.L., (2009), "Effect of fines on agglomeration in spray dryers: An experimental study", Int. J. Food Eng., Vol.5.

10. Filkova, I., Huang, L.X. and Mujumdar, A.S., (2007), Handbook of Industrial Drying, CRC Press Taylor and Francis Group, Boca Raton, pp. 223-224.

11. Ozkan, N., Walisinghe, N., and Chen, $X$. D., (2002), "Characterization of stickiness and cake formation in whole and skim milk powders", J. Food Eng. pp. 293-303.

12. Paterson, A.H.J., Brooks, G.F., Foster, K.D., and Bronlund, J.E., (2005), "The development of stickiness in amorphous lactose at constant $\mathrm{T}-\mathrm{T}_{\mathrm{g}}$ 
levels", Int. Dairy J., Vol. 15, pp. 513519.

13. Paterson, A.H.J., Bronlund, J.E., Zuo, J.Y., and Chatterjee, R., (2007), "Analysis of particle gun derived dairy powder stickiness curves", Int. Dairy J., Vol. 17, pp. 860-865.

14. Murti, R.A., Paterson, A.H.J., Pearce, D.L., and Bronlund, J.E., (2009), "Stickiness of skim milk powder using particle gun technique", Int. Dairy J., Vol. 19, pp. 137-141.

15. Gordon, M., and Taylor, J.S., (1952), "Ideal copolymers and the secondorder transitions of synthetic rubbers. I. Non-crystalline copolymers", Int. J. Appl. Chem., Vol. 2, pp. 493-500. 